\title{
CORRECTION
}

\section{Correction to: Letter to the Editor: Misquoting the ASD Prevalence Rate for Hong Kong: Comment on Tse (2020)}

\author{
Hannah M. Y. Tse ${ }^{1}$ (])
}

Published online: 3 March 2021

(c) Springer Science+Business Media, LLC, part of Springer Nature 2021

\section{Correction to: Journal of Autism and Developmental Disorders https://doi.org/10.1007/s10803-021-04870-8}

The on-line version of the article has error in corresponding author name in cite this article section in website.

This has been corrected in this erratum.

The Original article has been corrected.

Publisher's Note Springer Nature remains neutral with regard to jurisdictional claims in published maps and institutional affiliations. 